\title{
INFLUENCIA DEL TIPO DE NACIMIENTO SOBRE EL CONTENIDO DE BACTERIAS ACIDOLÁCTICAS EN MECONIO DE NEONATOS*
}

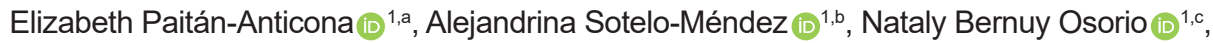 \\ Liliana Sumarriva-Bustinza (ii) ${ }^{2, \mathrm{~d}}$, Alejandro Norabuena Sotelo (i) ${ }^{1, \mathrm{e}}$ \\ Departamento de Nutrición, Universidad Nacional Agraria La Molina, Lima, Perú. \\ 2 Facultad de Ciencias, Universidad Nacional Enrique Guzmán y Valle, Lima, Perú. \\ a Ingeniero en Industrias Alimentarias, magíster Scientiae en Nutrición Pública; ${ }^{\mathrm{b}}$ ingeniero zootecnista, Magister \\ Scientiae en Nutrición; ' ingeniero en Industrias Alimentarias, doctora en Nutrición; ' químico farmacéutico, \\ doctora en Ciencias de la Educación; ${ }^{\mathrm{e}}$ médico cirujano. \\ * Parte de los resultados del artículo fueron presentados en calidad de póster en el XVIII Congreso Latinoamericano \\ de Pediatría - ALAPE que se desarrolló en Paraguay en septiembre de 2018
}

\section{RESUMEN}

El objetivo del estudio fue determinar la influencia del nacimiento por vía vaginal en comparación con el nacimiento por cesárea sobre el contenido de bacterias acidolácticas con características probióticas de los recién nacidos. Se evaluaron muestras de meconio de recién nacidos por vía vaginal y por cesárea que fueron debidamente enriquecidas, sembradas e incubadas. Las colonias resultantes fueron identificadas para ser sometidas a tolerancia de sales biliares, $\mathrm{pH}$ ácido y fermentación. Se obtuvo un mayor desarrollo de colonias en meconio de nacidos por vía vaginal en comparación con los nacidos por cesárea $(\mathrm{p}<0,001)$. Se aislaron 48 cepas en total, siendo en su gran mayoría tolerantes a sales biliares y pH ácido; asimismo, la fermentación de lactosa en leche fue positiva. Este estudio respalda hallazgos previos que sustentan que el nacimiento por vía vaginal favorece al mayor, desarrollo de bacterias acidolácticas con características probióticas, en comparación con el nacimiento por cesárea, y destaca la presencia de bacterias del género Lactobacillus.

Palabras claves: Microbiota; Neonato; Parto Normal; Cesárea (fuente: DeCS BIREME).

\section{INFLUENCE FROM THE TYPE OF BIRTH ON THE CONTENT OF LACTIC ACID BACTERIA IN NEONATE MECONIUM}

Citar como: Paitán-Anticona E, Sotelo-Méndez A, Bernuy Osorio N, Sumarriva-Bustinza L, Norabuena Sotelo A. Influencia del tipo de nacimiento sobre el contenido de bacterias ácidolácticas en meconio de neonatos. Rev Peru Med Exp Salud Publica. 2020;37(1):93-98. Doi: https://doi.org/10.17843/rpmesp.2020.371.4251

Correspondencia: Elizabeth Paitán Anticona; Calle los Opalos 251. Urb. Covica, Huancayo, Perú; epaitananticona@gmail.com

Recibido: 06/02/2019

Aprobado: 08/01/2020

En línea: 19/03/2020

\section{ABSTRACT}

The study's objective was to determine the influence of vaginal birth compared to cesarean birth on the content of lactic acid bacteria with probiotic characteristics from newborns. Vaginal and cesarean section meconium samples of lactic acid were evaluated, which were duly enriched, seeded and incubated. The resulting colonies were identified to be subjected to bile salt tolerance, acid $\mathrm{pH}$, and fermentation. A greater development of meconium colonies was obtained in those born vaginally compared to those born by caesarean section $(\mathrm{p}<0.001)$. A total of 48 strains were isolated, the majority being tolerant to bile salts and acid $\mathrm{pH}$; likewise, the fermentation of lactose in milk was positive. This study supports previous findings that support vaginal birth favors the greatest development of lactic acid bacteria with probiotic characteristics, compared to cesarean birth, and highlights the presence of bacteria of the genus Lactobacillus.

Keywords: Microbiota; Newborn; Natural Childbirth; Cesarean Section (source: MeSH NLM).

\section{INTRODUCCIÓN}

Las bacterias acidolácticas poseen efectos benéficos en la prevención y en el tratamiento de enfermedades, especialmente en infantes y niños. Las investigaciones han demostrado la presencia de bacterias en el meconio y en la sangre del cordón umbilical de neonatos sanos ${ }^{(1)}, y$ 
que incluso los fetos a término no son microbiológicamente estériles ${ }^{(2)}$. La influencia en el contenido de la microbiota intestinal se da en gran medida en el nacimiento y depende del tipo de parto (vía vaginal o cesárea), del tipo de alimentación (leche materna o leche maternizada) e, incluso, del contacto íntimo que se establece entre la madre y el hijo.

Los géneros pertenecientes a la microbiota natural del intestino corresponden a Lactobacillus y Bifidobacterium, que se desarrollan de forma diferenciada según el tipo de parto. Se ha reportado la presencia de estas bacterias en el meconio de recién nacidos vía vaginal a los 10 días de vida; y posterior a los 30 días de vida en recién nacidos por cesárea ${ }^{(3)}$. Además, la colonización por lactobacilos en nacidos por vía vaginal se da en mayor proporción (59\%), en comparación con lo que sucede con los nacidos por cesárea (4\%), estos últimos son colonizados más a menudo por Clostridium difficile, bacteria que normalmente se encuentra en el sistema digestivo de personas hospitalizadas o que se encuentran en tratamiento con antibióticos ${ }^{(4)}$.

Durante el parto por cesárea se interrumpe la transmisión de bacterias de la madre al recién nacido, lo que ocurre normalmente a través de la vía vaginal, esto conlleva a un incremento de enfermedades como: enfermedad celíaca ${ }^{(5)}$, diabetes tipo $1^{(6)} \mathrm{y}$ obesidad ${ }^{(7)}$. En el Perú, el Ministerio de Salud reportó que en el 2015 los nacimientos por cesárea alcanzaron un porcentaje de $34,5 \%$, y que nueve regiones tuvieron valores por encima del promedio, entre las que destacan Tumbes (49,8\%), Tacna $(47,2 \%)$ y Lima (42,8\%).

Por lo tanto, el objetivo del presente estudio fue determinar si el tipo de nacimiento, vía vaginal o cesárea, influye en el contenido de bacterias acidolácticas con potencial probiótico, provenientes del meconio de neonatos humanos.

\section{EL ESTUDIO}

\section{Recolección de muestras}

Realizamos un estudio observacional analítico. Durante cuatro meses se extrajeron al azar 60 muestras de meconio de neonatos humanos de cero a tres días de vida, del Instituto Nacional Materno Perinatal (INMP) de Lima, 30 muestras correspondían a partos por vía vaginal y 30 a cesárea. Se consideraron 30 muestras por cada grupo de neonatos debido a que el promedio de nacimiento por día en el INMP es de 60.

\section{Aislamiento de bacterias}

Para el preenriquecimiento se adicionaron $18 \mathrm{ml}$ de caldo Man Rogosa Sharp (MRS) (Merck, Alemania) sobre $2 \mathrm{~g}$ de meconio en frascos estériles, que fueron incubados a $37^{\circ} \mathrm{C}$ por 24 horas ${ }^{(8)}$ en un laboratorio clínico particular. Seguidamente, las muestras fueron sembradas por duplicado en placas de agar MRS para bacterias acidolácticas (Merck, Alema-

\section{MENSAJES CLAVE}

Motivación para realizar el estudio: El parto es considerado la culminación de la gestación. En el Perú, desde el 2015, el $34,5 \%$ de los partos ocurren por cesárea, lo cual es posible que influya en el contenido de la microbiota intestinal, específicamente sobre las bacterias acidolácticas.

Principales hallazgos: Se encontró que el meconio de recién nacidos por vía vaginal tuvo mayor desarrollo de bacterias del género Lactobacillus en comparación con aquellos recién nacidos por cesárea.

Implicancias: El tipo de parto influye sobre el contenido de bacterias acidolácticas provenientes del meconio de neonatos, siendo más favorable el parto por vía vaginal.

nia) ajustadas a pH 5,5 e incubadas a $37^{\circ} \mathrm{C}$ por 24 a 48 horas en microaerobiosis. Después, las muestras fueron sometidas a tinción de Gram, detección de esporas y prueba de catalasa para bacilos grampositivos libres de espora; además, se realizó el conteo de colonias blancas y cremosas considerando las características correspondientes de color, tamaño, forma y aspecto ${ }^{(9)}$. Posteriormente, se seleccionaron dos colonias de bacterias grampositivas no esporuladas y catalasa negativa ${ }^{(10)}$, que fueron aisladas en agar MRS y MRS modificado e incubadas a $37^{\circ} \mathrm{C}$ entre 24 y 48 horas en microaerobiosis. Seguidamente, las cepas aisladas fueron inoculadas en tubos de caldo MRS e incubadas a $37^{\circ} \mathrm{C}$ por 24 horas, para después ser centrifugadas a $8000 \mathrm{~g}$ por cinco minutos. Finalmente, se extrajo el sobrenadante y se añadió $1 \mathrm{ml}$ de caldo MRS y 40\% de glicerol para su almacenamiento a $-80^{\circ} \mathrm{C}$.

\section{Tolerancia a sales biliares}

La prueba se realizó en el Laboratorio de Microbiología y Biotecnología de la Facultad de Zootecnia de la Universidad Nacional Agraria la Molina (UNALM)). Se utilizó 0,5 ml de inóculo activado por 18 horas en caldo MRS que fueron adicionados a tubos que contenían $0,3 \%$ de sales biliares de origen bovino (Sigma, New Zealand) y $4,5 \mathrm{ml}$ de caldo MRS; lo cual se incubó a $37^{\circ} \mathrm{C}$ por 24 horas ${ }^{(11)}$. Las muestras fueron leídas en un espectrofotómetro a $600 \mathrm{~nm}$ (Thermo Scientific, modelo Genesys 10S UV-VIS), y los resultados, expresados como densidad óptica. Además, se calculó el porcentaje de sobrevivencia (R) mediante la relación entre log UFC/ml de muestra con sales biliares y el log UFC/ml de muestra sin sales biliares $^{(12)}$.

\section{Tolerancia al $\mathbf{p H}$ ácido}

Se añadió $0,5 \mathrm{ml}$ de inóculo a tubos en alícuotas de $4,5 \mathrm{ml}$ de caldo MRS a pH 3,0 acidificado con $\mathrm{HCl} 6 \mathrm{M}^{(11)}$. Estas muestras fueron activadas durante 18 horas en caldo MRS e incubadas a 
$37^{\circ} \mathrm{C}$ por 24 horas para medir la resistencia por densidad óptica a $600 \mathrm{~nm}$ (Thermo Cientific, modelo Genesys 10S UV-VIS), para finalmente calcular $\mathrm{R}$ respecto a la referencia ${ }^{(12)}$.

\section{Prueba de fermentación de lactosa de la leche}

La prueba consistió en inocular 3\% de las cepas en $20 \mathrm{ml}$ de leche pasteurizada $(3 / 100 \mathrm{v})$ que fueron incubadas a $37^{\circ} \mathrm{C}$ por 18 horas, para finalmente medir el $\mathrm{pH}$ final ${ }^{(12)}$. Esta prueba se realizó en el Laboratorio de Ecología Microbiana y Biotecnología de la Facultad de Ciencias de la UNALM.

\section{Análisis estadístico}

Los datos registrados para determinar la presencia de bacterias acidolácticas en el meconio de los recien nacidos por vía vaginal y por cesárea fueron analizados por duplicado. Para evaluar la normalidad se utilizó la prueba de KolmogórovSmirnov. Para evaluar las diferencias en el promedio de colonias según el tipo de parto, se usó la prueba U de Mann Whitney mediante el programa SPSS v. 20. Mientras que para analizar las pruebas de resistencia al $\mathrm{pH}$ ácido y a las sales biliares, se usó la prueba T de Student mediante el programa estadístico $\mathrm{R}$ versión 3.4.0.

\section{Consideraciones éticas}

El estudio tuvo la aprobación del Comité de Ética de Investigación del INMP. El propósito de la investigación fue explicado a las madres de los neonatos, quienes brindaron el consentimiento para extraer las muestras.

\section{HALLAZGOS}

\section{Recolección de muestras}

Las muestras de meconio de los nacidos por cesárea fueron de color amarillo verdoso, mientras que las muestras de meconio de los nacidos por vía vaginal tuvieron coloración negro verdo-

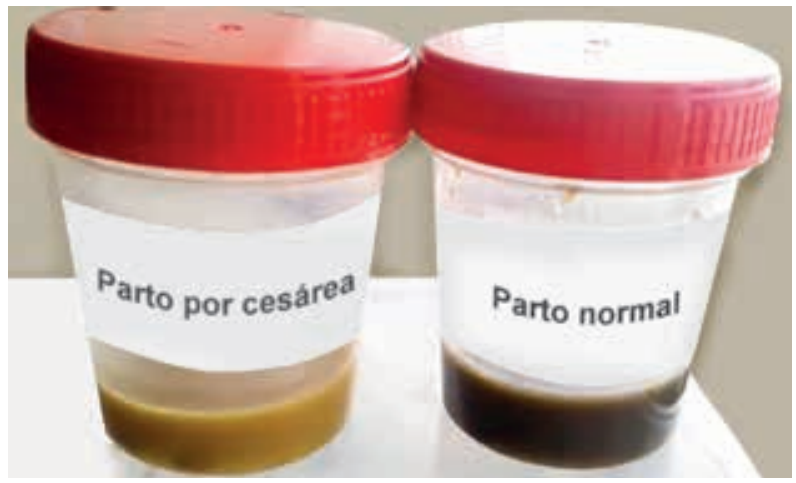

Figura 1. El meconio de neonatos tuvo una coloración amarillo verdoso debido a la alimentación con leche de fórmula en los nacidos por cesárea (izquierda) y tuvo un color verdoso en neonatos alimentados con leche materna nacidos por vía vaginal (derecha) so (Figura 1). Durante la recolección de meconio, se tuvo diferencias en las muestras de dos neonatos nacidos por cesárea, los cuales correspondían a neonatos de tres días de vida; el resto de muestras correspondía a neonatos de un día de vida. Asimismo, 28 de los neonatos nacidos por cesárea fueron alimentados con fórmula artificial y dos de ellos con leche materna a partir del tercer día de vida; mientras que aquellos nacidos por vía vaginal tuvieron lactancia materna exclusiva.

\section{Aislamiento de bacterias}

En la etapa de preenriquecimiento, dos muestras de meconio de recién nacidos por cesárea formaron gases que desprendían olores desagradables, las cuales se procedieron a sembrar en medio MacConkey. Luego de la incubación, se confirmó la presencia de colonias de enterobacterias.

En la prueba de crecimiento en placa, 28 de 30 muestras de meconio de recién nacidos por vía vaginal presentaron crecimiento de colonias de bacterias acidolácticas (93,3\%) comparado con dos de 30 muestras de meconio de los nacidos por cesárea (6,7\%) (Figura 2). Asimismo, el promedio de colonias fue mayor en el meconio de los nacidos por vía vaginal $(p<0,001)$ (Tabla 1$)$. Estas colonias fueron observadas al microscopio, y se encontraron bacilos largos delgados y bacilos cortos, que corresponden a características de bac-
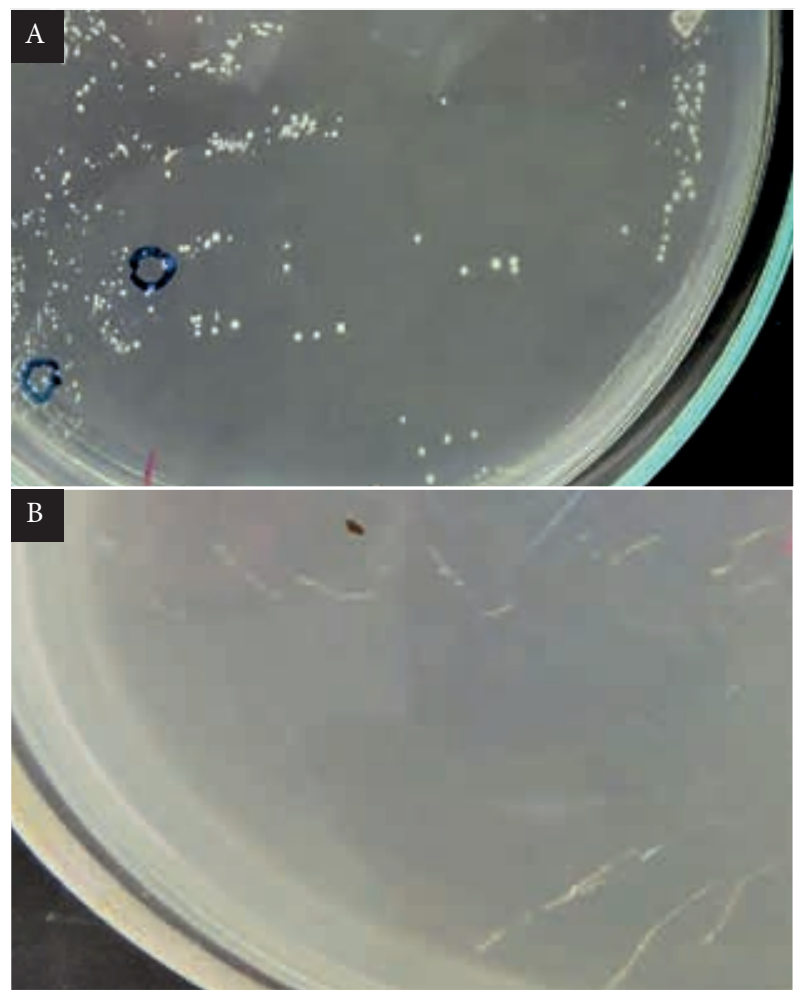

Figura 2. Crecimiento de colonias en agar MRS (Man Rogosa Sharp). A) Se evidencia mayor crecimiento de bacterias acidolácticas de recién nacidos por vía vaginal, B) En comparación con los nacidos por cesárea 
Tabla 1. Recuento de bacterias acidolácticas desarrolladas en agar MRS (Man Rogosa Sharp) y prueba de resistencia al pH ácido, en recién nacidos por vía vaginal y por cesárea

\begin{tabular}{|c|c|c|c|c|c|}
\hline & \multicolumn{2}{|c|}{ Vía vaginal } & \multicolumn{2}{|c|}{ Cesárea } & \multirow{2}{*}{ Valor de $\mathrm{p}$} \\
\hline & Valor & Rango $^{a}$ & Valor & Rango $^{\text {a }}$ & \\
\hline $\begin{array}{l}\text { Recuento de colonias BAL (UFC/g), } \\
\text { mediana (RIC) }\end{array}$ & $0,78 \times 10^{6}\left(0,6 \times 10^{6}\right)$ & 0,0 a $2,14 \times 10^{6}$ & $8 \times 10^{3}\left(4 \times 10^{3}\right)$ & 0,0 a $22,7 \times 10^{3}$ & $<0,001^{\mathrm{b}}$ \\
\hline Resistencia al pH ácido, media (DE) & $3,95(0,18)$ & 3,71 a 4,71 & $3,92(0,07)$ & 3,82 a 4,08 & $0,0001^{c}$ \\
\hline
\end{tabular}

${ }^{\mathrm{a}}$ Mínimo-máximo; ${ }^{\mathrm{b}}$ prueba U de Mann Whitney; ${ }^{\mathrm{c}}$ prueba T de Student

RIC: rango intercuartílico; DE: desviación estándar; BAL: bacterias acido lácticas, UFC: unidades formadoras de colonias

terias acidolácticas ${ }^{(9)}$. Se lograron aislar, en total, 48 colonias que se sembraron en medio MRS modificado, y se observó una mejor diferenciación de las colonias según su tamaño, color y borde (Figura 3).

\section{Tolerancia a sales biliares y al pH ácido}

Se aislaron 48 cepas de bacterias acidolácticas que fueron sometidas a una tolerancia $>30 \%$ de sobrevivencia para un lapso de 24 horas a un $\mathrm{pH}$ ácido de 3,0, y >20\% de sobrevivencia para una concentración de $0,3 \%$ de sales biliares. Se obtuvo un total de $33(68,7 \%)$ cepas sobrevivientes con mayor resistencia al ácido que a las sales biliares, medidos por absorbancia.

\section{Prueba de fermentación en leche}

Todas las cepas aisladas fermentaron la lactosa de la leche, obteniéndose un $\mathrm{pH}$ promedio de 3,95 $\pm 0,22(3,71 \leq \mathrm{pH} \geq 4,71)$.

\section{DISCUSIÓN}

Se evidenció que el meconio de recién nacidos por vía vaginal posee mayor presencia de bacterias acidolácticas que el meconio de recién nacidos por cesárea, y escasa presencia de organismos anaerobios.

El crecimiento de bacterias acidolácticas en las muestras de meconio de recién nacidos por vía vaginal está relacio- nada con la mayor cantidad de lactobacilos que presenta la vagina de la mujer y que, durante el parto, se transmite y coloniza la mucosa del tracto digestivo, respiratorio, urogenital y piel del neonato ${ }^{(13)}$. La colonización intestinal se da especialmente por el género Lactobacillus, lo cual contribuye a la formación de la microbiota en los neonatos ${ }^{(14-15)}$. Por lo tanto, consideramos que el mayor crecimiento de bacterias acidolácticas en el meconio de recién nacidos por vía vaginal se debió al aporte de la madre al pasar a través del canal del parto y a la lactancia exclusiva que recibieron.

Por el contrario, el meconio de recién nacidos por cesárea evidenció una mayor presencia de enterobacterias, lo cual estaría directamente relacionado con la presencia de los géneros Clostridium, Staphylococcus, Propiobacterium y Corynebacterium en el tracto digestivo de estos neonatos ${ }^{(14-15)}$. Además, las investigaciones recientes señalan que los nacidos por cesárea carecerían de colonización intestinal, o que esta se presentaría tardíamente, incluso hasta un año de edad ${ }^{(16)}$. Por lo que, el bajo crecimiento de bacterias acidolácticas en el meconio de recién nacidos por cesárea $(6,7 \%)$ estaría relacionado con el poco consumo de leche materna al tercer día de vida, ya que se ha reportado la presencia de bacterias lácticas (Lactobacillus, Staphylococcus, Streptococcus y Bifidobacterium) en la leche materna, que es transmitida al neonato al ser amamantado ${ }^{(17)}$.

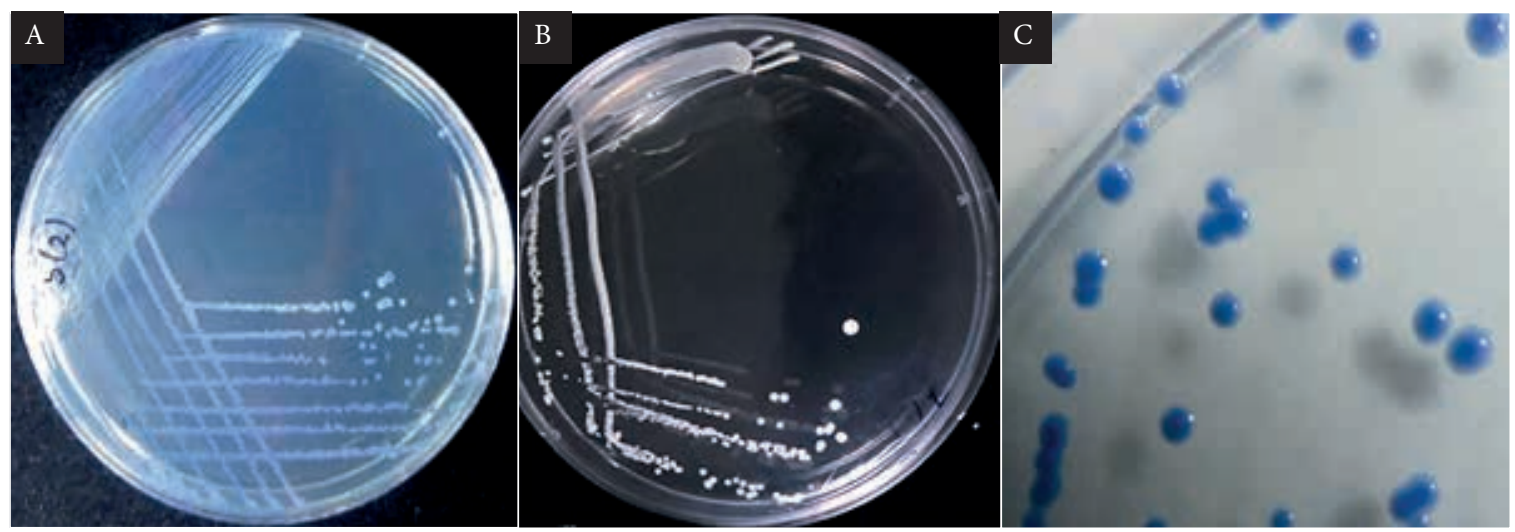

Figura 3. Aislamiento de colonias en agar MRS (Man Rogosa Sharp) proveniente del meconio de recién nacidos por vía vaginal. A) Agar MRS modificado con azul de bromofenol para diferenciar colonias de bacterias acidolácticas. B) Agar sin MRS modificado para crecimiento. C) Agar MRS modificado con colonias aisladas de forma redonda característico de bacterias acidolácticas 
El color amarillo verdoso y el olor intenso característico de las heces de los recién nacidos por cesárea, presumiblemente sea por la alimentación con leche de fórmula, a diferencia de lo observado en los recién nacidos por vía vaginal que se alimentaron primordialmente con leche materna ${ }^{(13)}$.

Las características descritas de las colonias de color blanco contabilizadas y seleccionadas en medio sólido corresponden a la descripción de bacterias acidolácticas del género Lactobacillus ${ }^{(9)} \mathrm{y}$, al crecer en caldo MRS presentaron precipitación rápida de células de color blanco al fondo del tubo, lo que ocurre cuando el crecimiento culmina dando lugar a un sedimento suave y homogéneo ${ }^{(18)}$.

Del total de cepas aisladas de bacterias acidolácticas el $68,7 \%$ presentó resistencia a las condiciones gastrointestinales durante un tiempo de exposición de 24 horas medidos por absorbancia, este valor es menor al $73,3 \%$ reportado para Lactobacillus ramosus expuesto por dos horas ${ }^{(19)}$, la diferencia podría estar relacionada con el tiempo de exposición. Es probable que las cepas sobrevivientes fuesen Lactobacillus casei (ATCC 27139, FAGRO 98, FAGRO 98LP) y Lactobacillus rhamnosus (FAGRO 36.5), ya que se ha reportado su resistencia al $\mathrm{pH}$ ácido y a altas concentraciones de sales biliares, que incluso sobreviven en el tracto gastrointestinal ${ }^{(20)}$.

Todas las bacterias acidolácticas aisladas fermentaron la lactosa de leche y el $\mathrm{pH}$ promedio registrado fue de 3,95, el cual se encuentra dentro del rango de Lactobacillus spp. ${ }^{(12)}$.

\section{REFERENCIAS BIBLIOGRÁFICAS}

1. Harmsen HJM, Wildeboer-Veloo ACM, Raangs GC, Wagendorp AA, Klein N, Bondels JG, et al. Analysis of intestinal flora development in breast-fed infants by using molecular identification and detection methods. J Pediatr Gastroenterol Nutr. 2000;30(1):61-7.

2. Jiménez EA. Fuentes de bacterias para la colonización del intestino del neonato: aplicación para el tratamiento de la mastitis lactacionales. [Tesis Doctoral]. Madrid: Universidad Complutense de Madrid; 2010 [citado el 20 de junio de 2017]. Disponible en https://eprints.ucm. es/10063/1/T31541.pdf

3. Grönlund MM, Lehtonen OP, Ferola E, Kero P. Fecal microflora in healthy infants born by different methods of delivery: permanent changes in intestinal flora after cesarean delivery. J Pediatr Gastroenterol Nutr. 1999;28(1):19-25.

4. Mitsou EK, Kirtzalidou E, Oikonomou I, Liosis G, Kyriacou A. Fecal microflora of Greek healthy neonates. Anaerobe. 2008;14(2):94-101. doi: 10.1016/j.anaerobe.2007.11.002

5. Marild K, Stephansson O, Montgomery S, Murray JA, Ludvigsson JF. Pregnancy outcome and risk of celiac disease in offspring: a nationwide case-control study. Gastroenterology. 2012;142:39-45. doi: 10.1053/j. gastro.2011.09.047

6. Aumeunier A, Grela F, Ramadan A, Pham Van L, Bardel E, Gomez Alcala A, et al. Systemic Toll-like receptor stimulation suppresses experimental allergic asthma and autoimmune diabetes in NOD mice. PLoS ONE. 2010;5(7):e11484. doi: 10.1371/journal.pone.0011484

7. Blustein J, Attina T, Liu M, Ryan AM, Cox LM, Blaser MJ, et al. Association of caesarean delivery with child adiposity from age 6 weeks to 15 years. Int J Obes (Lond). 2013;37(7):900-6. doi: 10.1038/ijo.2013.49

8. Moreno R, Salas EJ, Pérez CI, Jiménez J. Evaluación del potencial probiótico de Lactobacilos aislado de heces de lactantes y leche materna. Rev Fac Med ULA. 2011;20(1):135-9.

9. Kandler O, Weiss G. Regular nonsporing Gram positives rods. En: Sneath PHA, Mair NS, Sharpe ME, Holt JG, editors. Bergey's
Entre las limitaciones es preciso mencionar que la extracción de muestras fue limitada a dos a tres por semana, por cada grupo evaluado. El intervalo de tiempo entre la obtención de cada muestra dependía de la defecación del neonato, lo que influía en su traslado al laboratorio para los análisis correspondientes. Sin embargo, una vez colectada, se la mantenía en condiciones adecuadas para evitar su contaminación y deterioro.

Finalmente, se puede concluir que el meconio de recién nacidos por vía vaginal presentó un mayor desarrollo de bacterias acidolácticas con una mayor presencia de bacterias del género Lactobacillus en comparación a los nacidos por cesárea, en quienes se evidenció la presencia de enterobacterias.

Agradecimientos: A la Dra. Luz Veliz Sedano y a la Dra. Aida Cordero por sus valiosos aportes al desarrollo del presente trabajo de investigación.

Contribución de autoría: EPA y LSB realizaron la concepción y diseño del artículo, y la recolección de datos. EPA, ASM, LSB y NBO realizaron el análisis e interpretación de datos y la redacción del artículo. ASM, NBO y ANS realizaron la asesoría técnica y administrativa. Todos los autores aprobaron la versión final del artículo.

Fuentes de financiamiento: La investigación fue financiada con recursos propios y con el apoyo económico de la Fundación para el Desarrollo Agrario de la Universidad Nacional Agraria La Molina.

Conflictos de interés: Los autores de la presente comunicación declaran que no tienen ningún conflicto de interés.

Manual of Systematic Bacteriology. Vol 2. Baltimore: Maryland; 1986. pp. 1208-60.

10. Mejía-Rodríguez JA, Chacón- Rueda Z, Guerrero-Cárdenas B, Ottoniel-Rojas J, López-Corcuera G. Obtención de cepas de Lactobacillus: Caracterización in vitro como posible potencial probiótico. Rev Cientif. 2007;17(2):178-85.

11. Lara C, Burgos A. Potencial probiótico de cepas nativas para uso como aditivos en la alimentación avícola. Rev Colomb Biotecnol. 2012;14(1):31-40.

12. Sánchez L, Omura M, Lucas A, Pérez T, Llanes M, Luce C. Cepas de Lactobacillus spp. con capacidades probióticas aisladas del tracto intestinal de terneros neonatos. Rev Salud Anim. 2015;37(2):94-104.

13. Gritz EC, Bhandari V. The Human Neonatal Gut Microbiome: A Brief Review. Front Pediatr. 2015;3:17. doi: 10.3389/fped.2015.00017

14. Biasucci G, Rubini M, Riboni S, Morelli L, Bessi E, Retetangos C. Mode of delivery affects the bacterial community in the newborn gut. Early Hum Dev. 2010;86(1):13-5. doi: 10.1016/j.earlhumdev.2010.01.004

15. Madan JC, Salari RC, Saxena D, Davidson L, O‘Toole GA, Moore JH, et al. La colonización microbiana del intestino en neonatos prematuros predice la sepsis neonatal. Arch Dis Child Fetal and Neonatal Edition. 2012;97(6):F456-62.

16. Jakobsson HE, Abrahamsson TR, Jenmalm MC, Harris K, Quince C, Jernberg C. Decreased gut microbiota diversity, delayed Bacteroidetes colonisation and reduced Th1 responses in infants delivered by caesarean section. Gut. 2014;63(4):559-66. doi: 10.1136/ gutjnl-2012-303249

17. Solís G, De los Reyes-Gavilan CG, Fernández N, Margolles A, Gueimonde M. Establishment and development of lactic acid bacteria and bifidobacteria microbiota in breast-milk and the infant gut. Anaerobe. 2010;16(3):307-10. doi: 10.1016/j.anaerobe.2010.02.004 
18. Holt JG, Krieg NR, Sneath PHA, Staley JT, Williams ST. Bergey's Manual of Determinative and Bacterology 9a ed. Washington: National Academy Press; 2001.

19. Rodríguez Gonzáles M. Aislamiento y selección de cepas del género Lactobacillus con capacidad probiótica e inmunomoduladora. [Tesis Doctoral]. Barcelona: Universidad de Barcelona; 2009 [citado 20 enero 2019]. Disponible en: https://www.tdx.cat/bitstream/handle/10803/3931/mrg1de1.pdf

20. León Reissig MF. Evaluación in vitro de cepas de bacterias acidolácticas nativas con potencial probiótico. [Tesis de Licenciatura]. Montevideo: Universidad de la Republica; 2012. [citado 12 marzo 2019]. Disponible en: https://www.colibri.udelar.edu.uy/jspui/handle/20.500.12008/1432

\section{¿CÓMO ENVIAR UN ARTÍCULO A NUESTRA REVISTA? $\quad$ O}

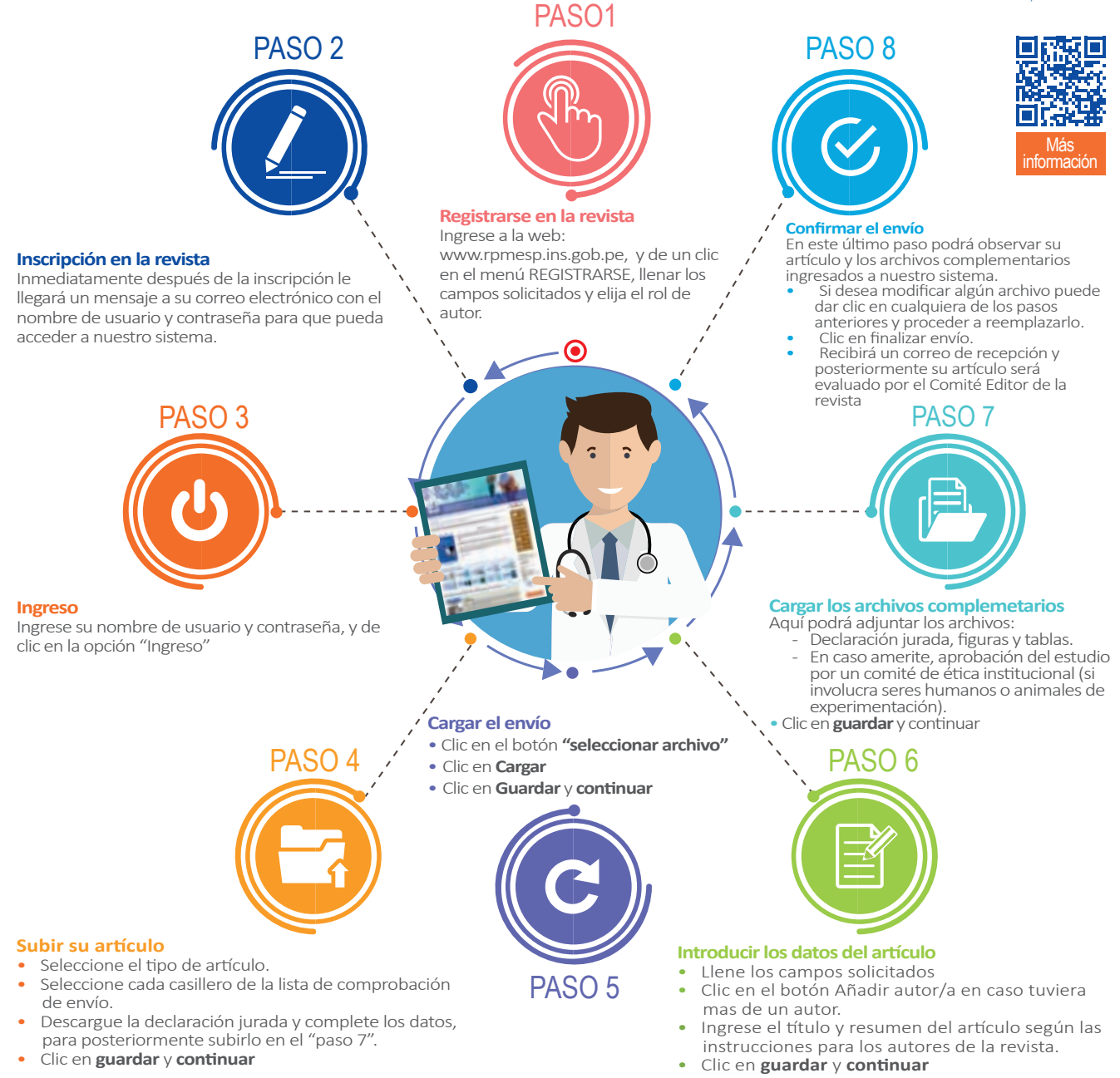

